Mens

Revue d'histoire intellectuelle et culturelle

mens

\title{
Gaétan Gervais : témoin et agent d'une mutation référentielle en Ontario français
}

\section{François-Olivier Dorais}

Volume 13, numéro 2, printemps 2013

URI : https://id.erudit.org/iderudit/1025983ar

DOI : https://doi.org/10.7202/1025983ar

Aller au sommaire du numéro

Éditeur(s)

Centre de recherche en civilisation canadienne-française

ISSN

1492-8647 (imprimé)

1927-9299 (numérique)

Découvrir la revue

Citer cet article

Dorais, F.-O. (2013). Gaétan Gervais : témoin et agent d’une mutation référentielle en Ontario français. Mens, 13(2), 59-99.

https://doi.org/10.7202/1025983ar
Résumé de l'article

Cet article propose une analyse des dimensions intellectuelle et historienne de l'oeuvre de Gaétan Gervais, professeur d'histoire à l'Université Laurentienne de 1972 à 2008, dans son rapport avec le processus de recomposition des cadres de référence identitaire en Ontario français depuis la fin des années 1960 jusqu'à nos jours. En revisitant certains segments de son itinéraire intellectuel et professionnel, l'étude fait apparaître l'historien comme l'une des principales figures énonciatrices d'une représentation identitaire axée sur une continuité référentielle avec le Canada français, porteuse d'une ambition autonomiste. Suivant l'examen de son positionnement épistémologique, l'analyse présente, en dernière instance, quelques pistes de réflexion autour des enjeux liés à la pratique de l'histoire dans les milieux minoritaires. 


\title{
Gaétan Gervais : témoin et agent d'une mutation référentielle en Ontario français ${ }^{1}$
}

\author{
François-Olivier Dorais \\ Département d'histoire \\ Université de Montréal
}

\section{Résumé}

Cet article propose une analyse des dimensions intellectuelle et historienne de l'œuvre de Gaétan Gervais, professeur d'histoire à l'Université Laurentienne de 1972 à 2008, dans son rapport avec le processus de recomposition des cadres de référence identitaire en Ontario français depuis la fin des années 1960 jusqu'à nos jours. En revisitant certains segments de son itinéraire intellectuel et professionnel, l'étude fait apparaître l'historien comme l'une des principales figures énonciatrices d'une représentation identitaire axée sur une continuité référentielle avec le Canada français, porteuse d'une ambition autonomiste. Suivant l'examen de son positionnement épistémologique, l'analyse présente, en dernière instance, quelques pistes de réflexion autour des enjeux liés à la pratique de l'histoire dans les milieux minoritaires.

\footnotetext{
${ }^{1}$ Le sujet de cet article a d'abord fait l'objet d'une thèse de maîtrise, soutenue à l'Université d'Ottawa en décembre 2012. Nous tenons à remercier tout particulièrement Michel Bock, notre directeur, de même que nos examinateurs, E.-Martin Meunier et Yves Frenette ainsi que les évaluateurs anonymes de la revue Mens pour leurs précieux conseils et commentaires autant sur la forme que sur le fond du texte. Nos remerciements vont également au Conseil de recherches en sciences humaines du Canada (CRSH) ainsi qu'au Fonds québécois de recherche sur la société et la culture (FQRSC) pour leur soutien financier.
} 


\section{Abstract}

This article proposes an analysis of the historical and intellectual dimensions of Gaétan Gervais's contribution to the re-composition of FrancoOntarian identity between the 1960s and today. By revisiting different episodes of the life of the man who was history professor at Laurentian University between 1972 and 2008, this article shows that the historian was one of the main architects of a frame of representation that created a sense of continuity between French-Canadian and French-Ontarian identities. This new framework also included an autonomist ambition at the institutional and referential levels. In examining his epistemological position, this analysis presents, in closing, a few thoughts on the practice of history and the role of historians within minority communities.

Pour peu que l'on s'intéresse à l'évolution récente de l'Ontario français, Gaétan Gervais apparaît comme une figure incontournable. Historien, intellectuel, conférencier, maitre à penser, professeur et homme d'action, il est à la fois le témoin et l'agent des multiples transformations vécues par la collectivité franco-ontarienne au cours des dernières décennies. Parmi celles-ci, l'éclatement de la " référence ${ }^{2}$ " canadienne-française, comme principe structurant le

${ }^{2}$ La notion de « référence " est empruntée ici à Fernand Dumont. Elle correspond au processus par lequel des individus intègrent dans leurs comportements, dans leurs discours, une identité qu'ils ont le sentiment de partager avec d'autres. Elle se situe sur le plan des "imaginaires collectifs » et désigne ce qui meuble la conscience de former une communauté (nationale ou autre), en regroupant l'idée d'une mémoire commune et d'une expérience historique partagée. La "référence " chez Dumont est de l'ordre de la culture seconde, c'est-à-dire qu' elle se constitue comme horizon, dans une mise à distance de la culture première qui est celle du quotidien et du monde empirique. Pour l'application de ce concept dans le contexte des francophonies minoritaires, voir Michel Bock, « De la solidarité canadiennefrançaise à l'éclatement des références : la mutation des identités québécoise et franco-ontarienne ", dans Jean-François Savard et Alexandre Brassard (dir.), Les relations Québec-Ontario : un destin partagé?, Québec, Les Presses de l'Université du Québec, 2011, p. 83-106; Stéphane Savard, «Une référence franco-ontarienne en mutation : émergence de nouvelles composantes identitaires franco-ontariennes 
sentiment d'identité et l'organisation de la vie sociale, est sans doute la plus significative. Cette mutation découle, pour l'essentiel, de l'accélération des phénomènes conjugués d'urbanisation et d'industrialisation après la Seconde Guerre, du déclin de l'Église comme institution d'encadrement social et politique, de l'émergence de l'État-providence, de la Révolution tranquille et de la montée du mouvement souverainiste au Québec. Par suite de ces transformations, la communauté française de l'Ontario est amenée à redéfinir les formes de son inscription dans l'espace social, institutionnel et identitaire. De fait, à compter des années 1970, ces nouvelles exigences donnent lieu à la formation d'un nouvel espace intellectuel franco-ontarien, soutenu par un réseau institutionnel en expansion, à l'intérieur duquel la condition de minoritaire peut être interrogée, puis débattue. Les nouveaux discours sur la communauté d'appartenance qui s'y forment - émanant principalement d'une communauté savante, enseignante, artistique, journalistique et associative, surtout laïque - viennent alors formuler autant de points de vue sur le type de société franco-ontarienne qu'il convient de conserver ou de bâtir.

Jusqu'à tout récemment, peu de chercheurs s'étaient penchés, dans une perspective résolument historique, sur la manière dont les intellectuels du milieu franco-ontarien ont problématisé leur dilemme identitaire ${ }^{3}$. Pourtant, les intellectuels, par leurs écrits, leur parole et leurs prescriptions, sont des acteurs qui contribuent puissamment à donner forme à l'espace référentiel d'une collectivité. Les historiens occupent, à cet égard, une fonction sociale singulière que Fernand

entre 1968 et 1984 sous le gouvernement Trudeau ", Bulletin d'histoire politique, vol. 15, n$^{\circ} 3$ (printemps 2007), p. 277-292.

3 À ce propos, on soulignera la contribution récente de l'historienne Marie LeBel qui demeure, à notre connaissance, la seule à avoir réalisé des recherches approfondies ayant spécifiquement trait à la constitution du " champ " intellectuel francoontarien contemporain (voir Marie LeBel, Le discours comme patrie : les intellectuels franco-ontariens comme interprétants de la condition historique et identitaire de l'Ontario français, thèse de doctorat (histoire), Québec, Université Laval, 2009). 
Dumont faisait correspondre à celle jouée par les poètes et les écrivains dans la construction des univers discursifs et mémoriels d'une collectivité. Comme le roman, disait-il, l'historiographie englobe tout « [...] un univers et un destin imaginaires dans lesquels [on] peu[t] plus ou moins [se] projeter, [se] voir ou [se] prévoir comme en une sorte d'horizon ${ }^{4}$ ".

C'est donc à partir de cet arrière-plan - celui de l'évolution d'une dynamique référentielle en Ontario français après les années 1960 et l'avènement d'une parole intellectuelle pour en faire sens - que le parcours et l'œuvre de Gaétan Gervais nous interpellent. Son itinéraire personnel et professionnel est celui d'un homme attentif à l'évolution de sa communauté d'appartenance, s'interrogeant sans cesse sur ses inquiétudes, ses espoirs et ses fragilités profondes. C'est le parcours d'un intellectuel "par vocation ", ayant pris une part active aux débats de la cité pour tenter d'influencer ses grandes orientations et d'insuffler à ses membres une certaine idée de leur destin collectif 5 . De même, son histoire nous plonge au cour des débats d'une société confrontée à ses propres indéterminations identitaires, entretenant un lien étroit et parfois en tension avec le rôle du politique et du savant.

Dans cet article, nous entendons montrer en quoi, d'une part, l'œuvre intellectuelle et historienne de Gaétan Gervais prend naissance dans le processus de recomposition identitaire de la collectivité francoontarienne par suite de l'effritement de la référence canadiennefrançaise et, d'autre part, comment elle tente de proposer une réponse à cette collectivité, un horizon du possible qui puisse prendre en compte les éléments de rupture qui travaillent son être collectif tout en cherchant à l'inscrire dans une continuité, c'est-à-dire dans le maintien d'un dialogue avec sa tradition nationale.

${ }^{4}$ Fernand Dumont, Fernand Dumont, un témoin de l'homme, entretiens colligés et présentés par Serge Cantin, Montréal, L'Hexagone, 2000, p. 93.

5 Dominique Foisy-Geoffroy, Les idées politiques des intellectuels traditionalistes canadiens-français, 1940-1960, thèse de doctorat (histoire), Québec, Université Laval, 2008, p. 44. 
Nous insisterons, surtout, sur les dimensions intellectuelle et historienne de l'œuvre de Gervais, en laissant de côté une partie de son œuvre militante, qui compte aussi une riche histoire, notamment en ce qui a trait au développement de l'éducation postsecondaire de langue française en Ontario et à la préservation du patrimoine francoontarien. Notre analyse repose principalement sur ses écrits marquants publiés, pour la plupart, entre 1977 et 2005 . Elle s'attache notamment à présenter l'historien comme l'une des principales figures énonciatrices d'une représentation identitaire axée sur une continuité référentielle avec le Canada français, porteuse d'une ambition autonomiste sur les plans institutionnel et référentiel.

Notre analyse se déroulera en trois étapes. Il s'agira, dans un premier temps, de retracer certains éléments marquants de la jeunesse de Gaétan Gervais susceptibles de nous renseigner sur le sens de son œuvre. Dans un deuxième temps, nous reviendrons sur le contexte socioculturel et identitaire de l'Ontario français des années 1970, en montrant comment Gervais y coule les fondations d'une conception particulière de l'identité franco-ontarienne et d'un projet historiographique. Dans un troisième temps, nous analyserons certains de ses écrits publiés dans les décennies subséquentes, période au cours de laquelle Gervais oriente sa carrière en histoire franco-ontarienne pour devenir l'un des principaux interprétants de la condition commune des Franco-Ontariens. Cela nous permettra, en définitive, de mettre en évidence son positionnement épistémologique, qui, en conjuguant désir de justice et de vérité, façonne un rapport particulier à l'objet d'étude.

\section{Les années 1960 : une personnalité intellectuelle en gestation}

Gaétan Gervais naît à Sudbury le 10 août 1944. Le petit quartier ouvrier du Moulin-à-fleur, un important foyer de la vie catholique française sudburoise, est celui de sa toute première enfance. Son père, Lionel Gervais, après avoir cumulé une expérience dans les secteurs 
agricole et forestier, travaille pour l'entreprise minière Inco. Sa mère, Claire Gervais, née Savage, est femme au foyer et s'occupe de la première éducation des cinq enfants. Au début des années 1960, alors qu'il est collégien chez les jésuites du collège du Sacré-Cour de Sudbury, Gaétan Gervais se plonge dans les livres de philosophie catholique et de littérature française. Comme plusieurs de ses confrères, il vit cette expérience comme un exil par rapport à son milieu d'origine. "Ma vie bascule. C'était comme arriver dans un autre monde, un univers différent ${ }^{6}$ ", confiera-t-il à son biographe. Le collège est alors un haut lieu de formation catholique et nationaliste (dans le sens canadien-français du terme), irrigué par les idées et les écrits de la Société historique du Nouvel-Ontario et du chanoine Lionel Groulx, qui s'y rendra à au moins deux reprises pour donner des conférences ${ }^{7}$. Au contact des œuvres, notamment celles du grand historien Arnold J. Toynbee - qui n'était pas indifférent au sort des Canadiens français, chez qui il percevait une force de résilience hors du commun ${ }^{8}$ - Gervais développe rapidement une passion pour la discipline historique et souhaite, dès l'âge de seize ans, en faire une profession. Il s'implique aussi dans le journal étudiant du collège de même que dans la corporation d'archives du professeur d'histoire Guy Courteau, qui le prend sous son aile et lui fait lire la collection de la revue Laurentie, publiée entre 1957 et 1962 par l'Alliance laurentienne, une organisation indépendantiste québécoise de droite". C'est à ce moment que Gervais se " connecte " à son milieu - celui du nord de l'Ontario - de même qu'à sa communauté d'appartenance canadienne-française et son passé.

${ }^{6}$ Cité dans Robert Arsenault, Gaétan Gervais : le "gardien du dépôt ", Ottawa, Centre franco-ontarien de ressources pédagogiques (ci-après CFORP), 2012, p. 15.

7 Michel Bock, Quand la nation débordait les frontières: les minorités françaises dans la pensée de Lionel Groulx, Montréal, Hurtubise HMH, 2004, p. 377-378.

8 Arnold J. Toynbee, Civilization on Trial, New York, Oxford University Press, 1948 , p. 161.

9 Gaétan Gervais, entrevue, Sudbury, juillet 2011. 
Jeune étudiant, il se démarque rapidement par l'excellence de son dossier scolaire. Il est admis sans trop de peine au baccalauréat en histoire à l'Université Laurentienne. L'institution publique, nouvellement créée, adopte un mode de fonctionnement bilingue. Alors en pleine commission Laurendeau-Dunton, les débats sur le bilinguisme et le biculturalisme occupent une place prépondérante dans la vie étudiante du campus, où se côtoient quotidiennement les deux groupes linguistiques. Gervais y participe activement à titre de rédacteur français pour Le Lambda, le journal étudiant de l'université. En 1963, à 19 ans, il cosigne un article dans lequel il critique, non sans un certain radicalisme, l'idéologie du bilinguisme :

Ce mythe, très peu sacré, du bilinguisme est une force malheureuse qu'il importe de dénoncer avec empressement. La seule réponse possible est d'être intégralement français. Les attitudes tolérantes et libérales d'antan sont largement dépassées. Et nous, nous devons passer à l'action, l'intransigeance et une attitude sans compromis sont nécessaires pour assurer la survivance d'un français qui soit correct et authentique ${ }^{10}$.

Sa critique du modèle d'intégration bilingue révèle une pensée en formation, s'articulant déjà sur des paradigmes précis. Elle rappelle notamment l'un des fondements du groulxisme selon lequel la communauté nationale canadienne-française porterait en elle une existence et une « âme » foncièrement distinctes, voire inconciliables avec la conception mécaniste, individualiste et rationaliste de la société défendue par les valeurs libérales anglaises ${ }^{11}$. Elle évoque aussi une compréhension "englobante » de la culture et de l'histoire du Canada français, qui rappelle l'idée de " culture globale " développée par l'auteur Hubert Aquin dans un texte célèbre publié quelques années plus tôt ${ }^{12}$.

${ }^{10}$ James de Finney et Gaétan Gervais, "L'anglais s'impose ", Le Lambda, vol. 3, no 4 (20 février 1963), p. 4.

11 À ce sujet, consulter Frédéric Boily, "Lionel Groulx et l'esprit du libéralisme ", Recherches sociographiques, vol. 45, $\mathrm{n}^{\circ} 2$ (mai-août 2004), p. 239-257.

12 Hubert Aquin, "La fatigue culturelle du Canada français ", Liberté, vol. 4, no 23 (mai 1962), p. 299-325. 
L'année suivante, dans un essai d'histoire qu'il fait paraitre dans les pages du même journal, Gervais prend position en faveur de l'indépendance du Québec. Selon lui, " [1]a rupture que fut la Conquête en 1759-1760 marque une division importante non tellement à cause du passage de l'autorité coloniale de Paris à Londres, mais du fait que le mouvement naissant vers l'individualité politique, à peine commencé, ait subi un premier échec ${ }^{13}$ ". Ce passage n'est pas sans rappeler la thèse d'un Guy Frégault qui, dans son maître ouvrage La Guerre de la Conquête publié en 1955, soulignait la discontinuité radicale, la déstructuration et la désintégration profonde induites par cet événement tragique. Pour Gervais, le relèvement de la condition des Canadiens français doit passer par une « révolution totale » un " [changement] des cadres ». " [La nation], ne doit jamais se définir en fonction d'une autre personne collective ou politique, un corps hétérogène, ce qui équivaudrait à une aliénation où l'on cesse d'exister en soi $^{14}$ ", affirme-t-il. Son propos fait écho à tout un imaginaire de la décolonisation alors en vogue dans certains milieux intellectuels de l'époque.

Son engagement ne se limite toutefois pas à la publication d'articles dans le journal étudiant. En 1964, Gervais s'implique aussi activement, au côté du jésuite André Girouard, dans la création de l'Association des étudiants de langue française du nord de l'Ontario (ADELFNO), une organisation étudiante nationaliste canadiennefrançaise militant pour la création d'écoles secondaires françaises subventionnées par l'État. Cette expérience, qui l'amène devant la commission Laurendeau-Dunton à Toronto où il présente un mémoire, lui fait notamment prendre conscience de l'importance de l'engagement civique en milieu minoritaire. Son implication dans cette association sera toutefois de courte durée puisque dès 1966, après un contrat d'enseignement d'une année au collège du SacréCœur, Gervais quitte Sudbury pour suivre une formation supérieure

13 Gaétan Gervais, «De notre histoire », Le Lambda, vol. 4, no 7 (avril 1964), p. 4.

14 Ibid. 
en histoire à l'Université d'Ottawa. Il y obtient une maîtrise en histoire politique portant sur la vie et l'œuvre de Médéric Lanctôt, qui fera l'objet d'un article dans la grande série sur les idéologies au Canada français, dirigée par Fernand Dumont ${ }^{15}$. Gervais s'engage par la suite dans une recherche doctorale sur l'expansion du réseau ferroviaire québécois à la fin du XIX ${ }^{\mathrm{e}}$ siècle, thèse qu'il soutiendra en 1979, sous la supervision du professeur Marcel Hamelin ${ }^{16}$.

\section{Un historien dans une société en mutation (1970-1980)}

$\mathrm{Au}$ moment où Gervais intègre le Département d'histoire de l'Université Laurentienne comme chargé de cours, en 1972, ses champs d'intérêt dans les domaines de la recherche et de l'enseignement portent principalement sur l'histoire des entreprises et du commerce de détail au Canada ${ }^{17}$. Comme plusieurs historiens de sa génération, il adopte les perspectives et les méthodes d'analyse de l'histoire économique. Sa pratique est aussi fortement influencée par le renouveau épistémologique qui a cours dans le Canada français des années 1960 et qui amène la discipline historique à se redéfinir sur des fondements plus "scientifiques ", à la faveur d'une approche plus " objective " et " matérielle " dans l'étude des changements sociaux. Comme nous le verrons, ce souci des structures, en particulier des institutions, modélisera une large part du discours intellectuel et historien de Gaétan Gervais, et ce, tout au long de sa carrière.

15 Gaétan Gervais, «Un souverainiste du XIX siècle : Médéric Lanctôt 1838-1877 », dans Fernand Dumont, Jean Hamelin et Jean-Paul Montminy (dir.), Idéologies au Canada français : 1850-1900, Québec, Les Presses de l'Université Laval, 1971, p. 265-274.

16 Gaétan Gervais, L'expansion du réseau ferroviaire québécois (1873-1895), thèse de doctorat (histoire), Ottawa, Université d'Ottawa, 1979.

17 Voir notamment Gervais, L'expansion du réseau ferroviaire québécois (1873-1895); Gaétan Gervais, "Le réseau ferroviaire du nord-est de l'Ontario ", Revue de l'Université Laurentienne, vol. XIII, no 3 (février 1981), p. 35-83; Gaétan Gervais, "Le commerce de détail au Canada : 1870-1880 ", Revue d'histoire de l'Amérique française, vol. 33, no 4 (mars 1980), p. 521-556. 
Pour comprendre le cheminement intellectuel de l'historien sudburois au cours de la décennie 1970, il faut d'abord considérer que celui-ci évolue dans un contexte particulier dans lequel la collectivité franco-ontarienne cherche à se donner un horizon de sens et à s'affirmer sur le plan symbolique. De fait, comme l'ont déjà fait remarquer Marie LeBel, Danielle Juteau et Lise Séguin-Kimton, les discours scientifiques qui s'institutionnalisent en Ontario français vers la fin des années 1970 s’ancrent dans un espace réflexif déjà balisé non seulement par la littérature, mais aussi par diverses formes artistiques comme le théâtre, la poésie et la chanson qui tentent, à leur manière, de mettre en forme un nouvel espace social et identitaire $^{18}$. Considérons à présent l'un des principaux lieux de réaménagement de la conscience identitaire des Franco-Ontariens à cette époque et auquel Gervais ne restera pas indifférent : l'ébullition artistique et contre-culturelle de Sudbury.

\section{Le projet identitaire de la contre-culture franco-sudburoise}

À la faveur de plusieurs mesures de soutien et de redressement déployées par les gouvernements fédéral et provincial, la minorité franco-ontarienne, tout particulièrement celle qui évolue à l'Université Laurentienne de Sudbury, connaît un important éveil culturel au tournant des années 1970. Un intense foyer d'animation théâtrale et littéraire enflamme alors toute une jeunesse francophone dans la ville minière du nord de l'Ontario. La coopérative artistique $\mathrm{CANO}^{19}$ voit le jour au début de la décennie et remporte un vif succès. Ce mouvement, animé principalement par de jeunes étudiants nouvellement admis à l'Université Laurentienne de même que par quelques professeurs du Département de lettres françaises,

18 Danielle Juteau et Lise Séguin-Kimpton, "La collectivité franco-ontarienne : structuration d'un espace symbolique et politique ", dans Cornelius J. Jaenen, Les Franco-Ontariens, Ottawa, Les Presses de l'Université d'Ottawa, 1993, p. 265; LeBel, Le discours comme patrie, p. 232.

19 À ne pas confondre ici avec le très populaire groupe musical CANO-musique, qui sera l'une des nombreuses émanations de la coopérative. 
en particulier Fernand Dorais, un père jésuite originaire de SaintJean-sur-Richelieu venu s'établir à Sudbury en 1969, s'inspire de la contre-culture québécoise et californienne ${ }^{20}$. Il donne lieu à la création de nombreuses institutions culturelles franco-ontariennes telles que le Théâtre du Nouvel-Ontario, le journal étudiant Réaction, les Éditions Prise de parole, Théâtre Action, la Nuit sur l'étang, le centre d'art Le Moulinet, Cité-Nord et les "Cuisines de la poésie ", pour ne mentionner que celles-ci.

Pour peu qu'elle ait été étudiée par les historiens, cette manifestation franco-ontarienne de la contre-culture occidentale semble projeter de manière ambivalente un double imaginaire de l'enracinement et du détachement. D'un côté, ses animateurs cherchent à se réapproprier l'espace social franco-ontarien en privilégiant un art non pas issu de la tradition classique canadienne-française ou européenne, qu'ils estiment aliénant ${ }^{21}$, mais plutôt enraciné dans le patrimoine régional nord-ontarien, où le lecteur et le spectateur peuvent se reconnaître à la fois dans les lieux et la réalité socioéconomique de leurs semblables ${ }^{22}$. De l'autre, les artistes de la contreculture cherchent aussi à se redéfinir en marge du traditionalisme canadien-français et des importations culturelles européennes extérieures à leur réalité. Ils font de la rupture leur mot d'ordre et souscrivent de moins en moins à une conception de l'identité qui s'inscrit dans la logique du Canada français, entendue ici comme un certain idéal de la culture, porteur d'une référence nationale transcendant l'individu et le temps. La réapparition, durant cette période,

20 Sur les influences extérieures de la contre-culture franco-ontarienne, se référer à Gaston Tremblay, Prendre la parole : le journal de bord du grand CANO, Ottawa, Le Nordir, 1995 ; Robert Dickson, "La "Révolution culturelle” en Nouvel-Ontario et le Québec : opération Ressources et ses conséquences ", dans Andrée Fortin (dir.), Produire la culture, produire l'identité?, Québec, Les Presses de l'Université Laval, 2000, p. 183-202.

21 Voir, par exemple, le texte "Molière Go Home " cité dans Tremblay, Prendre la parole, p. 21.

22 Lucie Hotte, "Littérature et conscience identitaire : l'héritage de CANO ", dans Fortin (dir.), Produire la culture, produire l'identité?, p. 53-68. 
du néologisme "Nouvel-Ontario " pour désigner à la fois l'espace réel et imaginé du Nord ontarien évoque cet attrait pour le "nouveau ", celui d'un vécu dans l'ici et le maintenant, qui a pour conséquence le « rejet » de ce qui l'a précédé $e^{23}$. Les artistes de CANO feront, pour leur part, de la dualité linguistique l'une des caractéristiques centrales de leur conception de l'identité franco-ontarienne ${ }^{24}$. En présentant le Franco-Ontarien à l'image d'un être hybride, bilingue, résultat d'un clivage identitaire entre son appartenance à l'imaginaire culturel français et son intégration dans les structures sociales et symboliques de la majorité anglaise, le groupe CANO valorise une appartenance identitaire définie en fonction du reflet renvoyé par le miroir d'une réalité culturelle et sociale vécue au quotidien.

C'est donc avec ces mutations sociologiques et identitaires en toile de fond que Gaétan Gervais est amené à se positionner dans l'espace idéologique franco-ontarien des années 1970. Une part de son engagement intellectuel et de son travail d'historien peut être interprétée en fonction de ce contexte auquel il participera en retour.

\section{Une autre conception de l'identité franco-ontarienne}

Contrairement aux artistes de la contre-culture, Gaétan Gervais considère que l'Ontario français doit entrevoir son avenir dans un raccordement et une filiation identitaire et culturelle avec le Canada français. Le déploiement du drapeau franco-ontarien évoque un tel positionnement dans le contexte mouvementé des années 1970. L'histoire est désormais connue : c'est à l'occasion de la rentrée scolaire de l'automne 1975 que Gervais, toujours chargé de cours en histoire, réunit un groupe d'étudiants pour créer ce qui deviendra, quelques années plus tard, le symbole officiel de l'Ontario français ${ }^{25}$.

23 Johanne Melançon, «Le Nouvel-Ontario : espace réel, espace imaginé, espace imaginaire ", Québec Studies, vol. 46 (automne 2008-hiver 2009), p. 54 et 56.

${ }^{24}$ Voir Hotte, "Littérature et conscience identitaire ", p. 53-68.

25 Bien que le drapeau soit adopté comme symbole officiel de l'Ontario français par l'ACFO provinciale en 1977, il faudra attendre jusqu'en 2001 pour que le gouvernement provincial de l'Ontario le consacre comme emblème officiel de la 
L'événement fournit une clé supplémentaire pour comprendre le positionnement idéologique de Gaétan Gervais par rapport au mouvement contre-culturel du Nouvel-Ontario. C'est ce que l'on retient de cette citation de l'historien Guy Gaudreau qui, lors d'un entretien, expliquait en quoi la création d'un drapeau dans le contexte universitaire sudburois de l'époque était tout, sauf un geste neutre d'un point de vue idéologique :

Un drapeau, ça reste quelque chose d'assez traditionnel. Je pense que ces jeunes-là [ceux de la contre-culture] rêvent à autre chose, à une autre culture. Ce n'est pas leur référence. Ils sont très mondialistes dans leurs revendications, dans leur mouvement de contreculture. Je pense que le drapeau représente [à leurs yeux] quelque chose de plus élitiste. Ça fait vieux jeu... dans leur lecture des choses, les drapeaux ont amené des guerres. Ils n'y voient pas un symbole heureux. Ça ne s'inscrit pas dans la mouvance contreculturelle de l'époque ${ }^{26}$.

Il ne serait pas entièrement erroné de voir dans le déploiement du « lys et du trille " l'affirmation d'une identité franco-ontarienne géographiquement délimitée par les frontières de la province ontarienne. Face à l'effritement de la « référence " nationale canadiennefrançaise, la montée du nationalisme québécois et la redéfinition d'un imaginaire canadien sous le gouvernement de Pierre Trudeau, la minorité franco-ontarienne aspire à mettre en représentation la spécificité de son expérience collective, une ambition que peut, sans conteste, canaliser la création d'un drapeau. Toutefois, il importe de rappeler qu'il ne s'agit pas là du sens que cherchent à lui donner Gaétan Gervais et ses étudiants à l'origine. En effet, pour ces derniers, la création du drapeau marque moins un engagement clair en faveur de la consolidation d'une nouvelle identité géographiquement délimitée à l'Ontario qu'un rappel pour les Franco-Ontariens qu'ils

communauté. Pour plus de renseignements sur l'histoire du drapeau, se référer à Guy Gaudreau (dir.), Le drapeau franco-ontarien, Sudbury, Éditions Prise de parole, 2005.

26 Guy Gaudreau, entrevue, Montréal, janvier 2012. 
restent, en dépit de tout, porteurs d'une communauté d'histoire, celle de la nation française en Amérique du Nord. Pour l'historien sudburois, le drapeau "n'est pas le fruit d'une génération spontanée ", mais bien un projet qui s'inscrit d'abord dans une " continuité historique », à la suite du Carillon-Sacré-Cour (1903), du fleurdelisé (1948), de la proposition (sans suite) d'un drapeau franco-ontarien par la Fédération des sociétés Saint-Jean-Baptiste de l'Ontario (1964), etc. ${ }^{27}$ En ce sens, il rappelle l'appartenance des Franco-Ontariens à une aventure historique singulière et fondatrice, celle du Canada français. Cette intention est manifeste dans le discours d'inauguration du drapeau préparé par Gervais et Michel Dupuis, l'un de ses étudiants. L'allocution, prononcée le 25 septembre 1975, situe le déploiement du drapeau dans une trame historique, redonnant aux 360 ans d'enracinement français sur le territoire de l'Ontario une dimension mémorielle profonde et dynamique. Le discours rappelle notamment le moment où Champlain a arpenté pour la première fois, en 1615, les eaux de la rivière des Outaouais, de Mattawa, du lac Nipissing, de la rivière des Français jusqu’à la baie Georgienne. Il évoque la fondation des premiers établissements et les premières possessions territoriales pour ensuite raviver le souvenir de ces " milliers de Canadiens français » venus s'établir en Ontario aux XIX ${ }^{e}$ et $\mathrm{Xx}^{\mathrm{e}}$ siècles. La suite du texte est pour le moins évocatrice de la dimension politique que les créateurs du drapeau souhaitent insuffler à ce geste, une dimension qui, selon Gervais, avait toujours fait défaut à la contre-culture franco-sudburoise ${ }^{28}$. Il rappelle à nouveau l'importance pour l'Ontario français de se doter de structures qui lui sont propres :

Toute communauté doit posséder ses symboles : ils deviennent le moyen d'identification, le point de ralliement, l'affirmation de

${ }^{27}$ Cité dans Arsenault, Gaétan Gervais : le "gardien du dépôt ", p. 72.

${ }^{28}$ Gaétan Gervais, "La stratégie de développement institutionnel de l'élite canadienne-française de Sudbury ou le triomphe de la continuité ", Revue $d u$ Nouvel-Ontario, no 5 (1983), p 87, [En ligne], [http://ifolaurentienne.ca/wpcontent/uploads/2012/03/rno5.pdf]. 
l'appartenance au groupe. [...] Aujourd'hui, nous déployons notre drapeau, mais demain nous déploierons la force économique et politique nécessaire à notre épanouissement. Sans ces pouvoirs, nous n'avons pas d'avenir : notre programme d'action doit comporter en premier lieu l'acquisition de ces pouvoirs économiques et politiques ${ }^{29}$.

Le discours, faut-il le rappeler, est lu par Yvonne Lemieux, la veuve de Camille Lemieux, rédacteur en chef du journal L'Ami $d u$ peuple. Ce choix n'apparaît pas anodin non plus dans la mesure où Lemieux avait lui-même été un ardent défenseur de la thèse des deux nations fondatrices du Canada et partisan de l'idée selon laquelle la survie du Canada français dépend directement des institutions dont il dispose ${ }^{30}$. Ainsi, nous pouvons raisonnablement supposer que c'est d'abord dans un souci de réaffirmer la singularité de l'expérience historique franco-ontarienne et sa dimension fondatrice au Canada que Gaétan Gervais et les étudiants à l'origine du projet s'engagent à lui donner un ancrage symbolique dans l'espace public. On peut penser que cette exigence s'impose d'autant plus que le contexte se prête à la politisation des débats linguistiques, au moment où plusieurs dirigeants franco-ontariens et la Fédération des francophones hors Québec (FFHQ) refusent publiquement de se conformer à la logique du multiculturalisme canadien (officiellement adopté par le gouvernement fédéral en 1971) au motif que celui-ci risque de porter atteinte au statut particulier que leur a conféré le principe du biculturalisme ${ }^{31}$. Ainsi, le drapeau franco-ontarien, s'il témoigne de la recomposition du sentiment d'identité des Franco-Ontariens, vise surtout à rappeler

29 Tiré des archives personnelles de Michel Dupuis et cité dans Stéphanie St-Pierre, "Le drapeau franco-ontarien : "puissent ses couleurs nous rallier dans une nouvelle amitié et fraternité” 1975-1977 ", dans Gaudreau (dir.), Le drapeau franco-ontarien, p. 18-19.

30 Serge Dignard, Camille Lemieux et l'Ami du peuple 1942-1968, Sudbury, Société historique du Nouvel-Ontario, 1984.

31 Stéphane Savard, "Je t'aime, moi non plus", réceptivité et identités des membres des élites franco-ontariennes vis-à-vis du gouvernement Trudeau, 1968-1984, thèse de maîtrise (histoire), Québec, Université Laval, 2005, p. 82-90. 
les fondements historiques de l'Ontario français et à les inscrire symboliquement dans l'espace et le temps. Il s'agit donc d'amener la collectivité franco-ontarienne à se donner une représentation cohérente et substantielle d'elle-même, qui puisse tenir dans une synthèse entre la « nouvelle » identité franco-ontarienne provincialisée et l'ancienne identité canadienne-française. Une telle démarche nous semble, pour le moins, s'éloigner du projet identitaire véhiculé par les artistes de la contre-culture.

L'année suivante, lors du Congrès annuel de l'Association canadienne-française de l'Ontario (ACFO), tenu à l'Université Laurentienne, Gaétan Gervais prend à nouveau ses distances du mouvement contre-culturel franco-sudburois, à qui il reproche de vouloir faire de la culture, des arts, des loisirs et de la langue les seuls instruments de l'affirmation collective. Lors d'une intervention en assemblée, il dira :

Or si on regarde comment fonctionne une société, c'est bien évident, et c'est la priorité fondamentale que l'on ne devrait jamais perdre de vue - à savoir qu'il n'y a pas une société au monde qui puisse survivre sans posséder des assises économiques solides. Et puis quand on possédera ces assises économiques, le restant viendra par surcroît. Mais aussi longtemps que l'on passe notre temps à nous occuper des "bébelles ", et puis dans les bébelles là, je m'excuse auprès de ceux que ça pourrait affecter, mais en tout cas, la poésie, le théâtre et la chanson... toutes les choses qui finalement devraient être le glaçage sur le gâteau, ou le pain si vous voulez [en référence ici au thème du Congrès « Du beurre sur notre pain »]. Mais essentiellement ce qui nous manque, c'est le pain, parce que les fondements de toute vie sociale, culturelle et politique sont d'abord économiques ${ }^{32}$.

L'historien de l'Université Laurentienne est alors bien conscient d'une chose : pour une collectivité de plus en plus urbanisée, son

32 Paul Lapointe (réalisation) et Georges-André Prud'homme (production), J'ai besoin d'un nom, Montréal, Office national du film du Canada (ONF), 1978, enregistrement vidéo couleur, $55 \mathrm{~min}$. 
épanouissement culturel et social dépend, en partie, du dynamisme de ses structures économiques. En 1979, il publie un long article sur le sujet dans les pages du journal Le Nord dans lequel il rappelle l'importance, pour les Franco-Ontariens, d'assumer davantage leur participation à la société capitaliste nord-américaine. Il insiste notamment sur l'importance de favoriser la création de petites et moyennes entreprises (PME), mais, surtout, la création de coopératives dont il vante le caractère « éminemment démocratique » et accessible ${ }^{33}$.

Cet appel à investir dans des structures économiques autonomes indique, chez Gervais, le refus de considérer le discours symbolique et culturel comme unique horizon de l'expression identitaire des Franco-Ontariens. Le projet de l'Ontario français ne saurait se limiter, selon lui, à la reconquête d'un espace de culture, comme semblent le proposer les artistes de la contre-culture. Cette dimension de sa pensée est capitale pour comprendre la suite de son œuvre. En effet, Gervais sera de tout temps convaincu de la nécessité, pour l'Ontario français, de capitaliser sur l'autonomisation et la consolidation de son espace institutionnel (plutôt que culturel ou discursif). Pour lui, l'autonomie des institutions françaises est un principe qui découle du «paradigme politique » de l'égalité entre les deux peuples fondateurs. Elle s'inscrit, par ailleurs, en filiation directe avec une pensée de l'autonomie du politique défendue par l'élite traditionaliste canadienne-française ${ }^{34}$. Les institutions font, à ses yeux, fonction de lien social entre les membres d'une collectivité. Aussi, permettentelles une " adaptation à la modernité » en assurant « la continuité des valeurs et de la culture d'une part, et l'adaptation, par des emprunts ou des changements, aux conditions nouvelles d'autre part ${ }^{35}$ ». Ce faisant, leur santé et leur solidité représentent pour lui une condition de la cohésion et de la permanence de cette même collectivité.

33 Gaétan Gervais, «La vie économique des Franco-Ontariens », Le Nord, 5 septembre 1979 , p. H-20.

34 Gervais, «La stratégie de développement institutionnel », p. 84.

35 Gaétan Gervais, "Le Canada-Français : un phare allumé sur mille citadelles ", Francophonies d'Amérique, no 4 (1994), p. 166. 
Ainsi, il nous apparaît clair que Gaétan Gervais a toujours entretenu de profondes divergences de vues avec la doxa contreculturelle franco-ontarienne, tout particulièrement en ce qui a trait à la conception de l'identité franco-ontarienne. Alors que le milieu de la contre-culture envisage l'avenir en opposition avec la société canadienne-française, délivré en quelque sorte de la pesanteur de son histoire, Gaétan Gervais rappelle plutôt l'importance de la référence au passé national canadien-français dans la définition de l'identité. Dans un article publié au début des années 1980, il mettait d'ailleurs en garde ses lecteurs contre le «mythe " de la rupture qui s’est créé autour de la dynamique d'affirmation culturelle et identitaire des années 1970. Selon lui, le mouvement du Nouvel-Ontario serait aussi, et surtout, l'héritier d'une tradition :

Ce qu'il importe de retenir aussi de cette "explosion culturelle", c'est qu'elle s'inscrit dans la suite des activités qui se déroulaient autrefois dans la Salle Sainte-Anne, au Collège du Sacré-Cour, au Centre des Jeunes, quand ce n'était pas dans les salles paroissiales de la région. Qu'il s'agisse de théâtre, d'édition, de musique, de création artistique, toutes ces activités font partie d'une tradition. Renouvelée oui, révolutionnaire non [...] Ainsi, l'intensité de l'activité artistique ne doit pas faire oublier qu'elle marche dans les sentiers battus de la tradition ${ }^{36}$.

Gervais ne remet pas en cause le caractère nouveau et dynamique de l'ébullition culturelle qui marque cette époque. Sa critique vise plutôt la tendance à en faire un moment de " rupture » ou un moment " fondateur » de l'Ontario français contemporain, qui serait forcément opposé à la dynamique qui le précédait.

Selon Gervais, parce que le passé reste imbriqué dans le présent, il ne serait pas aisé pour la nouvelle génération de changer en profondeur les structures et l'univers des représentations. C'est bien parce que l'Ontario français est déjà quelque chose et dispose d'une expérience historique plusieurs fois centenaire à laquelle il peut se référer

36 Gervais, «La stratégie de développement institutionnel », p. 84. 
qu'aucun acteur social ne peut la remodeler à son image en l'espace d'une seule génération. C'est d'abord comme héritiers de la nation française en Amérique du Nord que Gervais appréhende les FrancoOntariens et leur identité. À ce propos, citons cette phrase, très évocatrice, qu'il écrit en $1995:$ : [...] pour bien marquer les continuités, soulignons [...] que "lidentité franco-ontarienne", comme "l'identité québécoise", et malgré des ruptures profondes, ne sera jamais que le prolongement de l' "identité canadienne-française", elle-même le prolongement de l" identité française" ${ }^{37}$. " Par la référence au Canada français et à l'Europe, Gervais réitère ici quelque chose de la profonde singularité du modèle d'intégration sociétal canadienfrançais et franco-ontarien, prolongeant la grande tradition culturelle française. L'œuvre que Gervais échafaude depuis près de quarante ans est, comme nous nous apprêtons à le voir, traversée par ce souci d'une continuité référentielle au passé canadien-français.

\section{Le projet historiographique de Gaétan Gervais}

L'engagement de Gaétan Gervais dans l'aménagement d'un espace d'encadrement, de concertation, de production et de reconnaissance spécifique à l'histoire des Franco-Ontariens est indissociable de la problématique identitaire que nous venons d'aborder. Il doit surtout être compris dans son rapport à l'éclatement du projet national canadien-français. En effet, l'émergence de la "nation québécoise ", comme sujet politique et nouveau référent identitaire durant les années 1960 et 1970, a un impact sur la production scientifique au Canada français. Ainsi, pour nombre d'historiens nouvellement formés, il ne s'agit plus de penser la nation canadienne-française à l'intérieur du cadre canadien comme peuple fondateur, mais de confirmer le Québec dans son nouveau statut de "société globale " ou d'État-nation potentiel ${ }^{38}$. Il va sans dire que cette mutation de

${ }^{37}$ Gaétan Gervais, "Aux origines de l'identité franco-ontarienne », Cahiers Charlevoix : I, Sudbury, Société Charlevoix et Éditions Prise de parole, 1995, p. 168.

${ }^{38}$ L'expression "société globale " a été développée par le sociologue Marcel Rioux pour permettre un déplacement du cadre analytique depuis la société canadienne- 
l'historiographie constitue un enjeu de taille pour les francophones hors Québec. En larguant une part du paradigme national canadienfrançais au profit du paradigme de la nation québécoise, plusieurs historiens québécois larguaient du même coup la problématique des minorités françaises qui, à leurs yeux, étaient irrémédiablement vouées à la disparition ${ }^{39}$. Dans le compte rendu d'un ouvrage publié en 1975 portant sur la situation de la recherche sur la vie française en Ontario, Gaétan Gervais fait le constat qu'une telle occultation existe dans l'historiographie des Franco-Ontariens. Dans sa remarque, il écorche au passage le laxisme des universités bilingues de la province :

Souvent dissimulée comme une chose presque honteuse, la vie franco-ontarienne sort peu à peu de l'ombre. [...] le bilan des recherches est maigre : partout, on aligne des questions pour lesquelles, souvent, il n'existe pas même des éléments de réponse. Cette faiblesse de la documentation et la carence des recherches expliquent sans doute l'absence de débats de fond : il n'existe pas d'interprétation générale susceptible de susciter des discussions sur l'ensemble de la vie franco-ontarienne. En ajoutant que nous pouvons compter sur les doigts d'une main les véritables spécialistes de l'Ontario français, on comprend le peu d'avancement obtenu jusqu'à ce jour : les deux universités « bilingues » de l'Ontario commencent à peine à s'intéresser à ces questions, et elles doivent porter une partie de la responsabilité pour la situation actuelle ${ }^{40}$.

Comme historien, Gervais entend remédier à cette situation. Ainsi, il participe, dès 1976, à la fondation de l'Institut franco-ontarien (IFO), voué à la création d'un milieu et à la fabrication d'outils

française vers la société québécoise. Voir à ce sujet, Gilles Bourque, Jules Duchastel et André Kuzminski, "Les grandeurs et les misères de la société globale au Québec ", Cahiers de recherche sociologique, n 28 (1997), p. 7-17.

39 Michel Bock, Quand la nation débordait les frontières, p. 31.

${ }^{40}$ Gaétan Gervais, "Centre de recherche en civilisation canadienne-française, Université d'Ottawa, Actes du colloque sur la situation de la recherche sur la vie française en Ontario. Tenu à l'Université d'Ottawa les 28 et 29 novembre 1974 " (recension), Revue d'histoire de l'Amérique française, vol. 30, n 1 (juin 1976), p. 110 et 112 . 
destinés à la promotion de la recherche dans le domaine nouveau des études franco-ontariennes. Pendant plus de vingt ans, Gervais sera tour à tour directeur, directeur adjoint, responsable de la documentation, de la recherche et des publications ainsi que trésorier de l'IFO. Il est aussi l'un des principaux collaborateurs dans d'autres secteurs d'activités de l'Institut, que ce soit la constitution de collections d'archives sur l'Ontario français, la mise en œuvre de divers projets de publication et le développement de programmes de recherche, l'organisation de colloques et de conférences ou encore la préparation de rapports de recherche ${ }^{41}$. On le voit aussi, dès 1977, prendre le relais du défunt Lorenzo Cadieux à la direction de la Société historique du Nouvel-Ontario, qu'il remet sur pied avec l'aide d'un groupe d'universitaires. La Revue du Nouvel-Ontario (RNO), dont il est membre du comité fondateur en 1978, est affiliée à l'IFO et se veut l'une des premières publications proposant un regard critique, académique et scientifique sur l'Ontario français. Plusieurs de ses premiers textes portant sur l'Ontario français figurent d'ailleurs dans les pages de cette publication, dont il devient le directeur pour l'année 1980-1981 et l'un des principaux collaborateurs durant les années qui suivront.

À maints égards, les tâches entreprises par Gaétan Gervais dans le milieu scientifique ontarien témoignent de l'orientation nouvelle dans laquelle s'engage l'historiographie franco-ontarienne au cours des années 1970. Cette dernière souhaite faire connaittre l'histoire d'une collectivité à partir de nouvelles sources documentaires plus riches. Il s'agit aussi de combler certaines insuffisances en s'attardant à d'autres facettes du passé, que ce soit l'histoire des populations franco-ontariennes, leurs origines géographiques, les caractéristiques de leur colonisation, la nature des institutions qu'elles ont développées, etc. Pour Gervais, une telle ambition représente une prise de parole proprement franco-ontarienne et s'insère dans le mouvement d'affirmation identitaire qui a cours. Elle favorise l'inscription de la culture

${ }^{41}$ Arsenault, Gaétan Gervais : le "gardien du dépôt ", p. 64. 
du groupe dans l'espace public, sa présence n'étant plus limitée aux lieux immatériels et invisibles du discours et des représentations. Dans un article publié en 1977, Gervais discute du lien crucial qu'il perçoit entre l'avancement des connaissances historiques sur l'Ontario français et la question du renforcement de ses assises identitaires comme collectivité distincte :

Parler des sources, des archives ou des instruments de recherche disponibles pour étudier les Franco-Ontariens du nord-est de l'Ontario, c'est-à-dire du Nouvel-Ontario, c'est un peu poser la question de l'identité culturelle de cette communauté et des éléments qui la définissent. Conservées le plus souvent par les institutions qui encadrent la vie franco-ontarienne, les archives sont un reflet des secteurs où les Franco-Ontariens ont été le plus actifs : d'où cette relation évidente entre le type d'archives conservées et la définition culturelle des Franco-Ontariens. On ne s'étonnera pas, par conséquent, de constater l'importance, je dirais presque l'hypertrophie, des secteurs de l'éducation et de la religion, ces deux pôles traditionnels de la francophonie ontarienne qui nous rappellent en même temps l'atrophie des autres secteurs ${ }^{42}$.

Son propos laisse ici filtrer l'esquisse d'un projet historiographique en devenir, attestant un mariage entre une nouvelle ambition scientifique - celle de la recherche sur des aspects inédits de l'histoire franco-ontarienne - et la quête d'un sentiment historique renouvelé. C'est en ce sens qu'il faut voir dans les travaux de l'historien sudburois, menés au cours des années subséquentes, une intention non seulement de développer un savoir historique à proprement parler, mais aussi d'insuffler à sa communauté d'appartenance un sentiment d'historicité, afin qu'elle puisse être maîtresse de son propre développement historique et s'en représenter l'origine et l'évolution dans le temps. Il serait donc insuffisant de dire de la production historiographique

42 Gaétan Gervais, "Les sources de l'histoire des Franco-Ontariens du NouvelOntario ", dans Gérald Thomas et al. (dir.), Actes du colloque sur les archives et recherches régionales au Canada français tenu à l'Université d'Ottawa les 17 et 18 février 1977, Ottawa, CRCCF et ACFAS, 1977, p. 99. 
de Gervais sur l'Ontario français qu'elle a pour unique fonction de restituer passivement les faits et gestes du passé. Elle est aussi productrice de sens pour les Franco-Ontariens, qui vivent alors une expérience d'incertitude identitaire. Voyons d'un peu plus près ce qu'il en est exactement.

\section{L'historien et l'intellectuel de l'Ontario français (1980-2005)}

À la fin des années 1970, hormis quelques recensions critiques, notices biographiques et comptes rendus bibliographiques, Gaétan Gervais est plutôt absent des publications émergentes sur l'Ontario français. Entre ses obligations d'enseignement, ses tâches administratives, la rédaction de sa thèse de doctorat et ses nombreux engagements en comités académiques et communautaires ${ }^{43}$, il reste peu de temps pour entreprendre de nouveaux projets de recherche et d'écriture. C'est au tournant des années 1980 et dans les décennies qui suivront qu'il réoriente définitivement sa carrière en histoire franco-ontarienne, en s'investissant dans de nouveaux sujets d'étude et en travaillant au développement ainsi qu'à l'enseignement des premiers cours sur l'histoire des Franco-Ontariens à l'Université Laurentienne $\mathrm{H}^{44}$. Comment expliquer ce virage professionnel?

43 Les principaux comités auxquels siège Gaétan Gervais au cours de la décennie 1970 sont les suivants : Comité central de CULON (Canayens de l'Université Laurentienne, Ontario Nord); Comité des affaires francophones (dont il sera le président de 1975 à 1976); Comité du service d'animation; Conseil des sciences sociales; Comité des programmes; Comité consultatif de l'École des sciences de l'éducation; Comité pour la structuration du fait francophone; Comité ad hoc de l'Association des étudiant(e)s francophones; Comité organisateur de la Franco-Fête laurentienne.

${ }^{44}$ Le premier cours en histoire franco-ontarienne mis sur pied par Gaétan Gervais est un cours interdisciplinaire de $3^{\mathrm{e}}$ année portant sur l'histoire, la science politique et la sociologie. Le cours vise à étudier " la population franco-ontarienne dans le temps et dans l'espace. L'histoire du groupe. L'éducation et les luttes scolaires. La question linguistique. La sociologie de la religion. La situation économique. Les groupes sociopolitiques organisés. Les élites traditionnelles et les nouvelles élites. La vie politique. Le folklore franco-ontarien. Les idéologies et le devenir des Franco-Ontariens » (voir Annuaire officiel de l'Université Laurentienne, 1978-1979). 
Plusieurs hypothèses peuvent être envisagées. Tout d'abord, comme nous l'évoquions précédemment, l'élargissement d'un espace de production et de connaissances scientifiques sur l'Ontario français au cours des années 1970 motive très certainement de nouveaux chercheurs, comme Gervais, à s'y investir. Cet élargissement ne concerne pas uniquement l'Université Laurentienne, mais aussi l'Université d'Ottawa, où se trouve le Centre de recherche en civilisation canadienne-française (CRCCF), puis l'Université de Toronto grâce aux activités scientifiques du Centre de recherche en éducation franco-ontarienne (CREFO). Ensuite, en 1978-1979, Gaétan Gervais soutient sa thèse de doctorat et devient professeur adjoint. Ce nouveau départ professionnel l'amène peut-être à réorienter ses recherches vers de nouveaux sujets d'étude. Il est possible aussi que cette réorientation professionnelle s'explique par la volonté de donner une légitimité aux études franco-ontariennes et, plus largement, aux programmes d'enseignement universitaire en français, dont il avait eu l'occasion de mesurer la précarité et les insuffisances au cours des années précédentes ${ }^{45}$. Cette quête de légitimité trouve d'ailleurs, au même moment, une certaine caution scientifique dans les nouvelles théorisations sur l'autonomie des communautés francophones, développées notamment dans le champ sociologique, et auxquelles Gervais s'intéresse manifestement ${ }^{46}$.

45 En effet, Gaétan Gervais avait souligné à maintes reprises, dès son entrée en fonction comme chargé de cours, l'urgence d'améliorer les structures d'enseignement pour les francophones de l'Université Laurentienne. En avril 1976, à la demande du Comité de bilinguisme et du Comité des affaires francophones de l'Université Laurentienne, il publie un rapport important intitulé "Pour une réforme des programmes en français à l'Université Laurentienne ". Le document, également connu sous le nom de "rapport Gervais ", tente de cerner les faiblesses des programmes destinés aux étudiants francophones de l'institution d'enseignement et propose, entre autres choses, que l'administration universitaire concède à sa minorité française une autonomie dans la programmation et la planification de ses programmes (voir Gaétan Gervais, "Pour une réforme des programmes en français à l'Université Laurentienne ", Archives de l'Université Laurentienne, Fonds G. Gervais, P187, boîte 61,18.3.

46 On pense, entre autres, ici aux travaux pionniers de Raymond Breton sur la notion sociologique de " complétude institutionnelle » que découvriront nombre 
À ce jour, Gaétan Gervais compte à son actif six ouvrages (dont il est l'auteur ou le coauteur), plus d'une dizaine d'outils bibliographiques, près de quarante articles scientifiques et chapitres de livres, sept recensions critiques et nombre de rapports, brochures, mémoires et documents de travail. S'ajoutent à cela plusieurs articles d'opinion publiés dans les journaux de même que plusieurs entrevues radiophoniques et télévisuelles. À l'analyse, son œuvre présente des positionnements historiographique, idéologique et épistémologique en lien avec les questionnements qui travaillent la conscience identitaire de la collectivité franco-ontarienne. Nous tâcherons ici de mettre en évidence quelques-uns de ces positionnements, en tentant de voir comment ils prennent place dans ses écrits portant sur l'histoire de l'Ontario français.

\section{L'historien de la permanence et de la continuité}

Dans un numéro de la Revue du Nouvel-Ontario paru en 1983 pour le centenaire de la ville de Sudbury, Gaétan Gervais publie un article que l'on peut qualifier de fondateur pour sa carrière d'historien et d'intellectuel en Ontario français. Proposant une réflexion sur « la stratégie de développement institutionnel de l'élite canadiennefrançaise de Sudbury ", ce texte permet de dégager un attribut fondamental de sa pensée et de son approche de l'histoire, soit le souci constant de mettre en évidence les éléments de permanence et de continuité dans le temps. Pour Gervais, « [l]'évolution des sociétés et de leurs élites ne se comprend que dans le long terme où les structures économiques et sociales se transforment; il se passe moins de choses significatives dans le court terme de la conjoncture ». Ainsi, ajoute-t-il, est-ce " par abus qu'on décrit chaque changement culturel

d'analystes de la francophonie ontarienne durant les années 1980. Cette théorie suggère que la survie d'une population minoritaire passe par le développement et la gestion de ses propres institutions. À ce sujet, lire Raymond Breton, "L'intégration des francophones hors Québec dans des communautés de langue française ", Revue de l'Université d'Ottawa, vol. 55, no 2 (1985), p. 77-99. 
comme une révolution. En vieillissant, chaque génération, éprouvant un sentiment grandissant d'éloignement de la nouvelle génération, saute vite aux conclusions; elle exagère les différences qui la séparent des jeunes ${ }^{47}$ ". Dans ces passages, on peut penser que Gervais répond à nouveau aux artistes de la contre-culture, pour qui le FrancoOntarien serait un "homme nouveau ", de moins en moins « canadien-français » dans ses valeurs, sa culture et son identité. Le propos révèle aussi une orientation méthodologique particulière selon laquelle l'effervescence de l'événement ne saurait fournir à lui seul une juste appréhension du monde et de l'existence. L'événement doit plutôt correspondre, selon Gervais, à quelque chose qui se situe dans la durée. Il porte le témoignage de mouvements de profondeur qu'une conception instantanéiste du temps ne peut révéler. La parenté épistémologique avec le mouvement des Annales en histoire est ici frappante, plus particulièrement en ce qui a trait à l'élargissement temporel proposé par l'historien Fernand Braudel (la «longue durée »), auteur que Gervais a longtemps fréquenté dans sa jeunesse ${ }^{48}$. Les passages cités mettent en évidence, par ailleurs, une certaine sensibilité traditionaliste, que Pierre Trépanier définit comme « une méthode pour aborder la dialectique du moment et de la durée ${ }^{49}$ " ou, encore, comme une " conscience de la continuité historique ${ }^{50}$ ". Ce projet ne s'entend pas comme une « répétition de l'autrefois, mais [bien comme] une marche en avant soucieuse du maintien dans l'être d'une culture, à travers ses mutations ${ }^{51}$ ». Gervais n'exprime pas autre chose lorsqu'il écrit à propos du Canada français, dans un article de 1991 portant sur l'enseignement de l'histoire :

Durer et innover, conserver en s'adaptant, inscrire le développement futur dans la continuité de son expérience historique, tel est le

\footnotetext{
47 Gervais, "La stratégie de développement institutionnel », p. 68-69.

48 Gaétan Gervais, entrevue, Sudbury, juillet 2011.

49 Pierre Trépanier, "Qu'est-ce que le traditionalisme? ", causerie-débat tenue à Montréal, 8 juin 2002, Club du 3 juillet, p. 10.

50 Ibid., p. 1.

51 Ibid., p. 14.
} 
défi du Canada français. Il importe pour une communauté de maintenir, d'une génération à l'autre, la mémoire de son passé, le souvenir des grandes étapes de son évolution, les moments importants et les grands noms qui l'ont façonnée. Bref, une communauté tire de son passé les leçons qui lui permettent de se situer dans le temps et dans l'espace, de se faire une idée de sa place sur terre ${ }^{52}$.

Persévérer dans l'être tout en se renouvelant, infléchir l'avenir par l'autorité du passé, tel est ce qui, en quelques mots, résume la manière dont Gervais appréhende le devenir du Canada français et de l'Ontario français. Ainsi, le passé, plutôt que de se présenter comme un ensemble de strates fossilisées, apparaît comme une source de sens dans le présent et le futur. Cette posture décrit, selon nous, une vision qu’il serait malavisé de réduire à une forme de "passéisme ", encore moins à un refus obstiné du "progrès ". Elle décrit plutôt une disposition de l'esprit foncièrement sceptique et critique face au monde social, récusant toute adhésion aveugle au changement radical et aux velléités émancipatrices de la collectivitée ${ }^{53}$.

On peut penser que cette insistance sur la continuité dans le discours de Gervais n'est pas non plus étrangère au contexte particulièrement mouvementé du début de la décennie 1980, alors que la francophonie ontarienne doit composer avec un ensemble de mutations politiques, culturelles et économiques susceptibles de redéfinir ses orientations futures et, accessoirement, son rapport au passé. Ces mutations sont liées, d'une part, aux débats entourant le rapatriement de la Constitution du Canada en 1982, alors que nombre de dirigeants de la francophonie, issus des milieux politique et communautaire ainsi que des intellectuels, déploraient l'échec de l'Ontario français de faire reconnaître des droits additionnels, en particulier la reconnaissance de la dualité nationale fondatrice et du

52 Gaétan Gervais, "Liminaire : l'enseignement de l'histoire au Canada français ", Éducation et francophonie, vol. 19, no 2 (août 1991), p. 2.

53 Foisy-Geoffroy, Les idées politiques des intellectuels traditionalistes canadiens-français, 1940-1960, p. 56. 
bilinguisme officiel en Ontario ${ }^{54}$. D'autre part, on peut penser que l'emploi d'un discours à teneur nationaliste et historique faisait contrepoids à la montée en force d'un discours néolibéral et individualiste, plus ou moins favorable, par ailleurs, à la hausse du financement public destiné à la minorité de langue française. Simultanément était déployé un important effort de repositionnement de certaines institutions déjà établies. L'ACFO provinciale décidait, par exemple, dès 1982, d'entreprendre une ronde de consultations en vue de mettre en place son nouveau "plan de développement global ». Il en va de même pour l'ACFO du Grand Sudbury qui, de son côté, s'apprêtait à devenir une société autonome sans but lucratif ${ }^{55}$. Sur un autre plan, l'accentuation considérable du flux de l'immigration francophone en Ontario au cours des années 1980 et 1990, fruit d'une libéralisation des politiques d'immigration canadiennes, venait poser le défi de la diversité ethnoculturelle ${ }^{56}$. L'apport de nouveaux arrivants francophones des quatre coins de la planète n'était pas sans provoquer certaines remises en question fondamentales, notamment en ce qui a trait aux modalités de transmission de la mémoire collective.

C'est en considérant ces divers éléments de contexte qu'il faut, nous semble-t-il, analyser les travaux historiographiques de Gaétan Gervais, en particulier, la manière dont il conçoit la thèse de la

54 Voir à ce sujet Christiane Rabier, "Les Franco-Ontariens et la Constitution ", Revue du Nouvel-Ontario, no 5 (1983), p. 37-49; Serge Dupuis, "On prévoyait le déluge! La résistance franco-ontarienne au rapatriement de la Constitution canadienne : 1977-1982 ", Revue du Nouvel-Ontario, n 33 (2008), p. 7-39; Serge Miville, "À quoi sert au Canadien français de gagner l'univers canadien sil perd son âme de francophone?" Représentations identitaires et mémorielles dans la presse franco-ontarienne après la "rupture " du Canada français (1969-1986), thèse de maîtrise (histoire), Ottawa, Université d'Ottawa, 2012.

55 Voir à ce sujet Michel Bock, "L'ACFO du Grand Sudbury Inc., 1982-1987 ", dans Guy Gaudreau (dir.), Bâtir sur le roc : de l'ACFÉO à l'ACFO du Grand Sudbury (1910-1987), Sudbury, Éditions Prise de parole et Société historique du Nouvel-Ontario, 1994, p. 131-190.

56 Pour les statistiques, voir Gaétan Gervais et Michel Bock, L'Ontario français : des Pays-d'en-Haut à nos jours, Ottawa, CFORP, 2004, p. 12. 
" rupture " avec le Canada français. Pour lui, s'il y a bel et bien lieu de parler de « rupture " au tournant des années 1960, encore faudraitil en préciser la nature. En réponse à la thèse avancée par l'historien Yves Frenette, selon laquelle les Canadiens français n'auraient pas survécu à «l'irrémédiable fragmentation des années 1960 » et désigneraient un peuple qui aujourd'hui " n'existe plus », Gervais écrit :

L'auteur [Yves Frenette] a bien raison de parler de la rupture des années soixante, mais cette mutation ne signifie pas nécessairement la «mort " d'un peuple. On peut douter qu'il soit possible de faire « mourir un peuple " dans une génération? [sic] À l'encontre des nombreux intellectuels québécois, apparemment impatients de démontrer les décès des minorités françaises, prenons un point de vue différent et argumentons que la nation canadienne-française n'a que changé de forme [nous soulignons]. Et, pour rester dans le thème de la mortalité, on pourrait alors réciter comme autrefois à la messe des morts : vita mutatur, non tollitur (la vie n'est que transformée, elle ne cesse pas). Il en va de même pour le Canada français, qui n'a pas encore disparu, quel que soit le souhait de ceux qui prédisent depuis un siècle sa fin imminente ${ }^{57}$.

Ainsi, la " rupture " que note Gervais correspond moins à un fait de culture qu'à un fait institutionnel et politique. Rupture institutionnelle, tout d'abord, qui désigne, d'une part, le désengagement des grandes institutions canadiennes-françaises, établies surtout dans la province de Québec, à l'endroit des minorités françaises du pays et, d'autre part, la présence nouvelle du gouvernement fédéral et des gouvernements provinciaux dans le soutien au développement des minorités linguistiques ${ }^{58}$. Ensuite, sur le fond, la rupture fut politique parce qu'elle marque la fin d'une tradition de solidarité avec le Québec, l'une des pierres d'assise du nationalisme canadien-français. Ainsi, lorsque Gervais écrit que les États généraux marquent « le dernier

57 Gaétan Gervais, "Compte rendu : Brève histoire des Canadiens français (de Yves Frenette) ", Liaison, n 99 (novembre 1998), p. 31.

58 Gaétan Gervais, "Aux origines de l'identité franco-ontarienne », p. 142. 
acte de l'histoire du nationalisme canadien-français ${ }^{59}$ ", il se réfère au nationalisme politique et institutionnel. Cela ne suppose pas forcément la disparition du peuple canadien-français, puisque doit lui survivre, d'après Gervais, une expérience culturelle et historique singulière à réactualiser et à prolonger.

Plutôt que de voir le Canada français comme une simple catégorie historique ou comme une curiosité de musée, Gervais considère qu'il doit persister en tant qu'acteur légitime dans les discours et les représentations des communautés francophones de même que dans la définition de leurs projets. Son ouvrage L'Ontario français : des Pays-d'en-Haut à nos jours, publié en 2004 et rédigé avec l'historien Michel Bock, offre un témoignage éloquent de ce désir de mettre en évidence une continuité historique proprement franco-ontarienne dans l'espace public. Le livre, qui se veut aussi un manuel d'histoire franco-ontarienne destiné aux élèves du secondaire ${ }^{60}$, présente une grande synthèse des quatre siècles de la présence française en Ontario. L'Ontario français s'y révèle comme une collectivité à part entière, distincte de l'ensemble canadien dont elle fait partie. Les événements qui marquent son existence sont mis en récit jusqu’à ses origines en Nouvelle-France.

\section{Penser et dire la spécificité franco-ontarienne}

La recherche historiographique menée par Gaétan Gervais a pour objet principal l'étude de l'Ontario français, plus particulièrement la période canadienne-française du passé de l'Ontario français. Deux objectifs distincts nous semblent la guider. Dans un premier temps, elle vise à cerner la part spécifiquement franco-ontarienne des enjeux et des faits du passé pour donner à cette collectivité une existence

59 Gaétan Gervais, «La participation de l'Ontario français aux États généraux du Canada français et l'Ontario 1966-1969 ", Cahiers Charlevoix : III, Sudbury, Société Charlevoix et Éditions Prise de parole, 1998, p. 233.

${ }^{60}$ Il s'agit ici du deuxième manuel d'histoire franco-ontarienne à voir le jour en Ontario français. Le premier à s'être lancé dans une telle entreprise est Robert Choquette avec la publication de L'Ontario français : historique, Montréal, Éditions Études vivantes, 1980. 
propre dans l'espace public. Dans un second temps, par-delà les différentes thématiques abordées dans ses travaux, on peut dire de son entreprise interprétative qu'elle cherche à présenter la formation et la construction, dans le temps et l'espace, d'une société canadiennefrançaise à part entière. Cette histoire est construite autour de moments forts et symboliquement très significatifs, lesquels font bien souvent l'objet central de ses analyses. Qu'il s'agisse des États généraux du Canada français, du Règlement 17, des jumelles Dionne, des congrès patriotiques, de l'école du Fort Frontenac, du rôle des paroisses dans la survivance du fait français en Ontario, de la participation des Canadiens français au commerce des fourrures à l'époque du régime anglais, de l'historiographie franco-ontarienne, de l'enracinement des sociétés d'histoire en Ontario français, de la contribution scientifique de Germain Lemieux ou, encore, de la première foulée de Samuel de Champlain et d'Étienne Brûlé en terre ontarienne, tous ces événements de l'histoire franco-ontarienne dont Gervais traite dans ses travaux constituent autant d'empreintes qui confirment la permanence de l'enracinement français dans la province. Sous sa plume, l'Ontario français devient une réalité historique formelle et cohérente. En restituant ainsi un parcours historique proprement franco-ontarien, les écrits de Gervais participent des nombreux discours sociaux qui contribuent à organiser, modeler et meubler la référence à un imaginaire et à un espace géographique particuliers à partir desquels la collectivité francoontarienne peut se définir.

Force est aussi de constater que l'historiographie que développe Gaétan Gervais à compter des années 1980 rejoint la perspective théorique adoptée, la plupart du temps, par ce qu'il convient d'appeler "l'histoire nationale ». En effet, dans la plupart de ses travaux, l'Ontario français n'est jamais présenté sous l'angle de sa fragmentation ou de sa division sociale. À de rares occasions, il s'intéressera, par exemple, aux différentes catégories sociales franco-ontariennes susceptibles d'avoir été marginalisées par la mise en avant d'un récit national, qu'il s'agisse ici de conflits sociaux, d'inégalités liées au genre, à la 
classe sociale, à l'ethnie ou encore aux différences intergénérationnelles. Mais, en définitive, ces thèmes, généralement privilégiés par les historiens du social, Gervais y accorde assez peu d'attention. Il importe toutefois de préciser que sa tendance à relativiser certains enjeux ou le parcours de certains acteurs ou de groupes à l'intérieur de la collectivité ne signifie pas pour autant qu'il en nie l'existence. Ce sont plutôt, faut-il le rappeler, les éléments de continuité qui intéressent l'historien sudburois, ce qui implique un souci particulier du "commun » et la nécessité de dégager un sens de la multitude des intérêts sociaux et des conflits. Sous sa plume, la société minoritaire est donc envisagée comme un sujet collectif, historiquement circonscrit dans le temps long, engagé dans des rapports de pouvoir permanents avec la majorité anglaise ${ }^{61}$ et animé par une intention historique singulière. L'accent est ainsi régulièrement mis sur la fraternité comme, par exemple, lorsqu'il évoque la "grande famille canadiennefrançaise ${ }^{62}$ ", expression largement utilisée par les penseurs nationalistes des générations précédentes pour qualifier le Canada français historique. De la même manière, ce sont davantage les grands événements au cours desquels s'est jouée l'existence de l'Ontario français en tant que "communauté » qui le préoccupent et auxquels il consacre ses principaux travaux. On en trouve un exemple éloquent dans son étude sur l'Ontario français et les grands congrès patriotiques où il

61 À ce propos, il y aurait lieu de discuter des études historiques de Gervais dans lesquelles il met en scène les " combats " livrés par les Canadiens français de l'Ontario pour le maintien de leur intégrité culturelle. Ces combats et ces luttes, que Gervais a notamment revisités dans ses travaux sur le Règlement 17 et les jumelles Dionne, semblent constituer, chez lui, une part importante de l'architecture historiographique des Franco-Ontariens.

${ }^{62}$ Gaétan Gervais, Des gens de résolution : $d u$ "Canada français " à l'" Ontario français ", Sudbury, Éditions Prise de parole, 2003, p. 22; Gaétan Gervais, « Les droits du français en Ontario, l'argumentation traditionnelle des élites à l'époque du Canada français ", dans Marc Cousineau (dir.), La communauté francoontarienne : un peuple, ses droits et son destin : actes du colloque tenu à Ottawa le 11 août 2000, Sudbury, Institut franco-ontarien, 2001, p. 50 ; voir aussi Gaétan Gervais, "L'histoire de l'Ontario français (1610-1997) ", dans Joseph Yvon Thériault (dir.), Francophones minoritaires au Canada : l'état des lieux, Moncton, Les Éditions d'Acadie, 1999, p. 157. 
explique en quoi, selon lui, ces rassemblements ont constitué un moment privilégié pour apprécier l'unité du projet national canadienfrançais :

L'unité de la pensée canadienne-française se traduisit de nombreuses façons, certes, mais se manifesta rarement avec plus d'éclats que lors des dizaines de congrès, tant patriotiques que religieux, qui ponctuèrent l'histoire de la nation canadienne-française. Ces rassemblements solennels fournirent aux élites, tant religieuses que laïques, l'occasion de se retrouver, de se concerter, de proclamer publiquement les hauts principes qui les inspiraient [...] Ainsi, les congrès devinrent eux-mêmes des "symboles ", de véritables structures de signification, représentatives de l'ensemble du Canada français ${ }^{63}$.

Cette insistance sur la dimension collective et commune des FrancoOntariens apparaît aussi dans son texte sur les régionalismes en Ontario français. Si, a priori, un tel sujet d'étude appelle une mise en évidence du caractère éclaté du groupe entre ses différentes régions physiographiques, géographiques, de peuplement, et ses divers pôles d'influence institutionnels, sa conclusion se veut un rappel du « sort commun » qui unit les Franco-Ontariens :

[...] peut-on parler de "régions » en Ontario français? Il semble que l'encadrement le plus significatif de la communauté soit le réseau institutionnel. Celui-ci est plus dense dans certaines villes qui exercent une place centrale dans chacune des trois régions reconnues [Ottawa, Sudbury et Toronto]. Toutefois, leur fonctionnement n'est pas bien connu, pas plus que les caractéristiques qui les distinguent. Les manifestations de patriotisme régional sont rares. Menacés au point de vue culturel, les Franco-Ontariens ont plutôt le sentiment de partager un sort commun $^{64}$.

${ }_{63}$ Gervais, Des gens de résolution, p. 18-19.

${ }^{64}$ Gaétan Gervais, "L’Ontario français dans toutes ses régions ", dans Société Charlevoix, Les régionalismes de l'Ontario français : actes de la table ronde de la Société Charlevoix : dixième Salon du livre de Toronto, Toronto, Éditions du GREF, 2005, p. 15. 
Ainsi, autant sa démarche aspire à un certain idéal de scientificité, autant elle garde pour préoccupation fondamentale de permettre à l'espace minoritaire franco-ontarien de perdurer en tant que lieu de socialisation et de transmission d'une culture et d'un héritage. L'un des exemples les plus probants où coexistent ces deux impératifs se trouve sans doute dans sa monographie sur les jumelles Dionne. Alors que plusieurs travaux ont été consacrés aux quintuplées dans la perspective d'un récit national canadien (c'est le cas notamment de l'historien Pierre Berton ${ }^{65}$ ), Gervais propose plutôt d'en faire un jalon de l'histoire franco-ontarienne : « [...] aucune étude d'ensemble, autre que les traductions, ne raconte en français l'histoire de celles qui furent, sans aucun doute, les Franco-Ontariennes les plus illustres de l'histoire ${ }^{66}$ ", écrit-il. Ce passage est lourd de signification dans la mesure où il montre comment l'historien sudburois entend associer ce fait d'histoire à une référence proprement franco-ontarienne plutôt qu'à une référence canadienne. Autrement dit, le récit qu'il propose est endogène à la collectivité et confirme celle-ci dans son historicité singulière et son caractère distinct des autres récits nationaux. L'objet d'étude est, quant à lui, posé comme une société ou, à tout le moins, comme une minorité nationale inscrite dans un cadre référentiel autonome.

Ainsi, on comprend mieux pourquoi Gervais, dans d'autres textes plus engagés, ne souscrira jamais aux thèses sur l' " hybridité " identitaire des Franco-Ontariens, c'est-à-dire à l'idée selon laquelle, parce qu'immergés dans un milieu bilingue, les Franco-Ontariens auraient à négocier une "double personnalité " ou une "identité dédoublée ». "La possession de deux cultures [est] un fantasme [...] ", de dire l'historien sudburois, fidèle en cela à ses opinions de jeunesse. "Cette idée de biculturalisme discréditée partout, ne sera qu’un masque pour déguiser l'acculturation, mot savant pour décrire le

65 Pierre Berton, The Dionne Years: A Thirties Melodrama, Toronto, McClelland and Stewart, 1977.

66 Gaétan Gervais, Les jumelles Dionne et l'Ontario français (1934-1944), Sudbury, Éditions Prise de parole, 2000, p. 17. 
processus d'assimilation ${ }^{67}$. " Gervais rejoint ici l'analyse du sociologue Roger Bernard selon laquelle l'identité «bilingue ", concept de plus en plus valorisé dans les représentations identitaires de la francophonie canadienne, ne serait en fait que le reflet du transfert de la culture française vers la culture anglaise ${ }^{68}$. Aux yeux de Gervais, " les "biculturels" sont absents de la communauté franco-ontarienne, ils ne participent pas à ses institutions, ils ont de moins en moins le sentiment d'en faire partie ${ }^{69}$ ". Autrement dit, ils ont abandonné l'espoir de construire une société franco-ontarienne "globale». De la même manière, Gervais entrevoit la substitution du terme "Canadien-Français » par celui de "francophone " comme une dégradation de l'identité des minorités françaises. Le bannissement du terme "Canadien-Français ", qu'il attribue notamment au lexique identitaire dénationalisant du Secrétariat d'État et à la diffusion du vocable "Québécois » et «francophone » par le mouvement néonationaliste québécois et la Société Radio-Canada, serait l'un des principaux symptômes du processus d'assimilation des minorités françaises, désormais réduites à leur stricte appartenance linguistique. «Dépouillé de toute connotation spécifique, le mot "francophone" trahit l'aliénation culturelle d'une communauté dont on attaque l'identité en la privant de son nom propre, canadien-français ou franco-ontarien. Quel genre de leadership nous prépare-t-on avec une telle conception de la culture, de la personne et de l'identitét ${ }^{70}$ ?"

67 Gaétan Gervais réagissait ici aux propos de la journaliste anglo-québécoise Sheila McLeod Arnopoulos, publiés en 1982 dans son ouvrage Hors du Québec, point de salut?, dans lequel elle discutait notamment de la double exigence culturelle des Franco-Ontariens (voir Gervais, "La stratégie de développement institutionnel ", p. 87).

68 Roger Bernard, "Du social à l'individuel : naissance d'une identité bilingue ", dans Jocelyn Létourneau (dir.), La question identitaire au Canada francophone, Sainte-Foy, Les Presses de l'Université Laval, 1994, p. 155-163.

69 Gervais, «La stratégie de développement institutionnel », p. 87.

70 Gaétan Gervais, "Préface », dans Guy Gaudreau (dir.), Du Centre des jeunes au Carrefour francophone 1951-1990: quarante ans de vie communautaire et culturelle à Sudbury, Sudbury, Société historique du Nouvel-Ontario, 1992, p. 9-10. 


\section{Positionnement épistémologique : réfléchir "à partir " de l'Ontario français}

Jusqu'ici, nous avons décrit quelques-uns des traits marquants de l'œuvre historienne et intellectuelle de Gaétan Gervais. Nous avons montré en quoi l'exercice de sa pensée et son écriture prennent la forme d'un geste d'engagement envers la construction d'une collectivité franco-ontarienne spécifique, à l'heure où cette dernière est en profonde transformation dans son rapport à elle-même. Or cette analyse de son travail d'historien appelle un questionnement plus large sur ses intentions fondamentales. À tout le moins, on serait en droit de se demander si Gervais inféode sa démarche scientifique à un quelconque projet politico-identitaire franco-ontarien. Une juste appréciation des fondements de sa pensée nous apparaît ainsi nécessaire pour éclaircir ce point puisque son positionnement épistémologique nous semble correspondre à certaines exigences propres à la pratique réflexive en milieu minoritaire.

Bien qu'il n'ait pas exercé de réflexivité sur son propre travail et sur la nature de son épistémologie, Gervais agit néanmoins conformément à une conception particulière du rôle de l'historien en société. À ce propos, il écrit dans un texte publié pour la première livraison des Cahiers Charlevoix (1995):

Que les historiens contribuent aux définitions identitaires, c'est une pratique qui se retrouve chez presque tous les peuples [...]. L'identité d'une communauté se fonde sur une certaine mémoire de son passé, sur une certaine compréhension de son expérience historique. Ainsi, il existe un lien entre l'histoire, tel que l'interprètent les chefs du groupe auquel on s'identifie, et l'identité qu'on veut mettre de l'avant. L'expérience historique résulte d'événements réels, mais le souvenir qu'on en garde se prête à bien des interprétations. La part du subjectif est donc importante dans la définition d'une identité, les faits et les événements passés étant sans cesse réinterprétés par les communautés ${ }^{71}$.

71 Texte publié à l'origine dans les Cahiers Charlevoix : I, p. 125-168, puis repris dans Gaétan Gervais, "Aux origines de l'identité franco-ontarienne », dans Des gens de résolution, p. 209. 
En injectant du sens dans les événements, l'historien établit, selon Gervais, un certain rapport au passé et propose une construction identitaire. L'histoire, telle qu'il la conçoit et la pratique en Ontario français, cadre avec une conception profondément engagée du savoir. À ce propos, l'historien Michel Bock disait, au sujet de Gervais, que " [l] savoir [qu'il] génère [...] depuis plus de trente-cinq ans, tout en étant scientifique - ou "honnête" -, n’en est pas moins "engagé", en ce sens qu'il contribue puissamment à construire la "sociéte" franco-ontarienne en tâchant d'en rappeler les "raisons communes" 72 ". Ainsi, le savoir, tel qu'il se déploie dans la démarche épistémologique de Gervais, se révèle indissociable de son enracinement singulier. Plutôt que de s'extraire de sa propre communauté socio-identitaire pour faire œuvre de connaissance, l'historien de Sudbury montre que c'est plutôt par l'intermédiaire de sa propre culture, de son appartenance communautaire et de ses référents qu'il formule ses questionnements et insuffle à sa société une part de vérité historique. Nous oserons ici le parallèle avec Fernand Dumont en disant du positionnement épistémologique de Gaétan Gervais qu'il consiste à réfléchir $\grave{a}$ partir d'une culture et non pas seulement sur une culture ${ }^{73}$. Autrement dit, toujours selon Dumont, il s’agit de placer «la mémoire [au] commencement de la méthode ${ }^{74}$ ". Cette autre belle formule du sociologue québécois résume bien, à notre avis, la pratique réflexive de Gervais, qui, lui-même, envisage la mémoire et l'histoire dans une relation plutôt étroite, l'une alimentant l'autre : «Comme la mémoire, l'histoire est un dialogue permanent du présent avec le passé. Elle exprime, à un moment donné, l'ordre que la raison introduit dans

72 Michel Bock, "Gaétan Gervais, l'Université Laurentienne et l'Ontario français : l'engagement d'un intellectuel historien ", conférence d'ouverture du colloque L'Université Laurentienne : berceau de la culture et de l'identité franco-ontariennes, Sudbury, 25 mars 2010.

73 Gérard Bergeron, "En souvenir du temps de notre jeunesse ", dans Simon Langlois et Yves Martin (dir.), L'horizon de la culture : hommage à Fernand Dumont, Sainte-Foy, Les Presses de l'Université Laval, Institut québécois de recherche sur la culture, 1995, p. 531-534.

${ }^{74}$ Fernand Dumont, Le sort de la culture, Montréal, L'Hexagone, 1987, p. 318. 
la masse des faits historiques ${ }^{75}$. " Ainsi, sous sa plume, l'histoire porte la mémoire des origines, la responsabilité d'un héritage, la construction et la préservation d'une culture particulière. "Si on n'enseigne pas l'histoire, affirme Gervais, l'étudiant ne développera pas le souci du contexte et de la relativité des vérités dites universelles. Il ne possédera pas le sentiment d'appartenir à une communauté spécifique [...] Car, sans histoire, nous n'héritons de rien ${ }^{76}$. " En souhaitant montrer la spécificité franco-ontarienne à travers l'histoire, Gervais cherche indirectement à fonder un sentiment d'identification à celle-ci. La méthode indique une certaine intention politique; celle de justifier le droit d'existence et la permanence de cette collectivité en tant que " minorité nationale » dans l'ensemble canadien.

Ce désir de justice, au cœur de l'épistémologie de Gaétan Gervais, côtoie donc, sans pour autant s'y opposer, un désir de vérité. Celui qui a lu les écrits de l'historien saura, en effet, reconnaittre l'empreinte d'une profonde rigueur empirique, soucieuse du respect des faits, manipulant avec prudence et empathie le contenu de la source de manière à restituer un rapport de qualité avec le passé. Y voir une démarche scientifique inféodée à un quelconque projet idéologique serait omettre de considérer le lieu historique et social singulier à partir duquel l'historien formule ses interrogations. Ce lieu, celui de l'Ontario français, est un espace minorisé, travaillé de l'intérieur par les impératifs de la survie culturelle et par l'inquiétude d'un devenir incertain. C'est ainsi, dirons-nous, par nécessité que l'historien sudburois développe une posture interprétative qui participe de l'expression d'une identité collective axée sur le particulier et la distinction. Cette perspective rejoint d'ailleurs ce qui nous semble être l'une des constantes de son œuvre d'historien, qui consiste à poser l'objet franco-ontarien comme une société et non comme une

75 Gaétan Gervais, «L'historiographie franco-ontarienne : à l'image de l'Ontario français ", dans Jacques Cotnam, Yves Frenette et Agnès Whitfield (dir.), La francophonie ontarienne : bilan et perspectives de recherche, Ottawa, Le Nordir, 1995, p. 123.

76 Gervais, «Liminaire : l'enseignement de l'histoire au Canada français », p. 2. 
composante, parmi tant d'autres, de la société globale canadienne. Dans ses écrits, la construction historique de l'Ontario français est envisagée dans son mouvement vers l'autonomie et l'autoréférentialité. Telle est l'exigence de pensée avec laquelle il exerce son métier. Elle décrit une pratique réflexive vécue comme une "pratique de solidarité ", pour le dire à nouveau avec Dumont, c'est-à-dire dans une dynamique d'identification, de complicité et d'appartenance à l'objet d'étude. On pourrait donc dire de la posture de Gervais qu'elle correspond en tout point à celle de l'intellectuel des "petites sociétés " et que Jocelyn Létourneau situait au croisement de deux exigences en tension, qui consiste à « impenser " son pays, à s'y mettre à distance, tout en lui vouant un amour profond qui commande une certaine responsabilité, une fraternité et une fidélité 77 .

\section{$\operatorname{sos} 08$}

Dans cet article, nous nous sommes intéressé aux dimensions intellectuelle et historienne de l'œuvre de Gaétan Gervais dans le contexte plus large des importantes mutations référentielles vécues en Ontario français au cours des dernières décennies. Nous avons tenté de montrer que l'historien sudburois a cherché, par ses écrits historiques et certaines de ses initiatives, à faire sens de ces mutations dans le dessein d'autonomiser une référence propre à l'Ontario français. Dans un espace identitaire en pleine reconfiguration, Gervais est de ceux qui ont cherché à inscrire l'identité francoontarienne et ses supports dans une continuité référentielle avec le Canada français, souhaitant, par là, réactualiser en Ontario français une prétention sociétale à l'autonomie et à l'autoréférentialité. En cela, il exprime le refus de percevoir cette collectivité comme le simple fragment ethnique d'une nationalité autre - la nationalité canadienne. C'est peut-être là que réside l'intérêt premier de son œuvre, soit de rappeler que le passé est une catégorie qui infléchit le

77 Jocelyn Létourneau, “"Impenser” le pays et toujours l'aimer », Cahiers internationaux de sociologie, vol. CV (1998), p. 361. 
présent; que l'existence de la collectivité franco-ontarienne n'est point le fruit d'une refondation ou d'un recommencement, mais plutôt le témoignage d'une étonnante continuité historique. Son œuvre pose ainsi l'épineuse question du sens collectif dans le contexte particulier des milieux minoritaires, dont la cohésion est aujourd'hui plus fragilisée que jamais par les effets de la mondialisation et la multiplication des demandes émancipatrices issues des mouvements sociaux et des revendications à fondement identitaire ${ }^{78}$. De la même manière, et dans une logique contraire à celle d'une modernité radicale, l'œuvre de Gaétan Gervais rappelle en quoi les cultures minorisées, comme celle de l'Ontario français, qui n'ont pas de territoire national ni la possibilité de transformer leur sentiment national en une pleine autonomie politique, ne peuvent, au risque de participer à leur propre disparition, se dérober de la référence à un ordre transcendant, qu'il s'agisse de l'histoire, de la mémoire ou de la tradition. Cette ouvre comporte également une interrogation plus large touchant la permanence et la rupture d'une visée nationale dans les représentations et la structuration identitaires de la francophonie ontarienne. À cet égard, il semble possible d'affirmer qu'en proposant une interprétation de l'Ontario français à travers le prisme de la dualité nationale et de l'autonomie, Gervais a été un agent structurant d'une dynamique de continuité nationale héritée du Canada français en Ontario. Son œuvre est révélatrice du phénomène selon lequel il persisterait, dans le discours et l'imaginaire des francophones de l'Ontario, une référence, ténue, mais toujours existante, au Canada français. En creux de cette posture se révèle aussi le propre d'une sensibilité " nationalitaire ", c'est-à-dire celle d'une forte aspiration à se percevoir en sujet national, mais qui se heurte abruptement à sa condition de minoritaire, dans laquelle les structures étatiques, économiques et sociales doivent être partagées

78 À ce sujet, lire Jacques Beauchemin, La société des identités : éthique et politique dans le monde contemporain, Montréal, Athéna éditions, 2005. 
avec la majorité ${ }^{79}$. Elle évoque la persistance de cette double et dialectique réalité - celle de l'autonomie et de l'intégration - qui oriente encore de nos jours les grands questionnements sur l'avenir de l'Ontario français et des francophonies minoritaires.

79 Joseph Yvon Thériault, "Entre la nation et l'ethnie : sociologie, société et communautés minoritaires francophones ", Sociologie et sociétés, vol. 26, no 1 (printemps 1994), p. 15-32. 